\title{
Brief Communication: Update on the GPS reflection technique for measuring snow accumulation in Greenland
}

\author{
Kristine M. Larson ${ }^{1}$, Michael MacFerrin ${ }^{2}$, and Thomas Nylen ${ }^{3}$ \\ ${ }^{1}$ Department of Aerospace Engineering Sciences, University of Colorado, Boulder, CO 80309, USA \\ ${ }^{2}$ CIRES, University of Colorado, Boulder, CO 80309, USA \\ ${ }^{3}$ UNAVCO, 6350 Nautilus Drive, Boulder, CO 80301, USA
}

Correspondence: Kristine M. Larson (kristinem.larson@gmail.com)

Received: 10 December 2019 - Discussion started: 3 February 2020

Revised: 14 May 2020 - Accepted: 15 May 2020 - Published: 18 June 2020

\begin{abstract}
GPS interferometric reflectometry (GPS-IR) is a technique that can be used to measure snow accumulation on ice sheets. The footprint of the method $\left(\sim 1000 \mathrm{~m}^{2}\right)$ is larger than that of many other in situ methods. A long-term comparison with hand measurements yielded an accuracy assessment of $2 \mathrm{~cm}$. Depending on the placement of the GPS antenna, these data are also sensitive to firn density. The purpose of this short note is to make public GPS-IR measurements of snow accumulation for four sites in Greenland, compare these records with in situ sensors, and make available open-source GPS-IR software to the cryosphere community.
\end{abstract}

\section{Introduction}

GPS interferometric reflectometry (GPS-IR) was first described and validated for measuring seasonal snow accumulation in the western US (Larson et al., 2009; McCreight et al., 2014). GPS-IR takes advantage of the fact that reflected GPS signals at low elevation angles from natural surfaces such as snow and ice are minimally rejected by geodetic antennas (Fig. 1). The interference between the direct and reflected GPS signals produces a characteristic pattern in signal-to-noise ratio (SNR) data that can be used to retrieve the height of the GPS antenna phase center above the top of the snow and ice surface. These vertical reflection distances (also called reflector heights, or RHs) are estimated for every rising and setting GPS satellite arc; a daily average RH is then computed. The daily $\mathrm{RH}$ measurement has a footprint of $\sim 1000 \mathrm{~m}^{2}$ at sites where the antenna height is $\sim 2 \mathrm{~m}$.
Three GPS receivers were installed on the interior of the Greenland ice sheet in 2011 by the GLISN project (Greenland Ice Sheet Monitoring Network; Clinton et al., 2014, Fig. 2). The original scientific application of these data was to precisely measure the three-dimensional movement of the ice sheets. Larson et al. (2015, hereafter L2015) showed that GPS-IR could be combined with GPS-derived vertical coordinates to provide information about both snow accumulation and firn density. L2015 summarized the GPS-IR technique and presented analysis of GPS-IR results for the period 2011-2014. Comparisons with another instrument (ultrasonic snow depth sensor) and regional atmospheric climate models were limited and qualitative. Since that time the GPS-IR technique has been successfully used in Antarctica (Siegfried et al., 2017; Shean et al., 2017). The former also compared GPS-IR retrievals with manual snow height measurements, yielding an accuracy assessment of $2 \mathrm{~cm}$. Since the GLISN deployment began, a new GPS-IR site, SMM3, has been added in Greenland at Summit Camp.

The goals of this brief communication are to

1. present and archive GPS-IR results for these four sites in Greenland

2. compare GPS-IR snow accumulation records with other in situ datasets

3. provide short descriptions and links to publicly available GPS-IR software for the cryosphere community to use. 


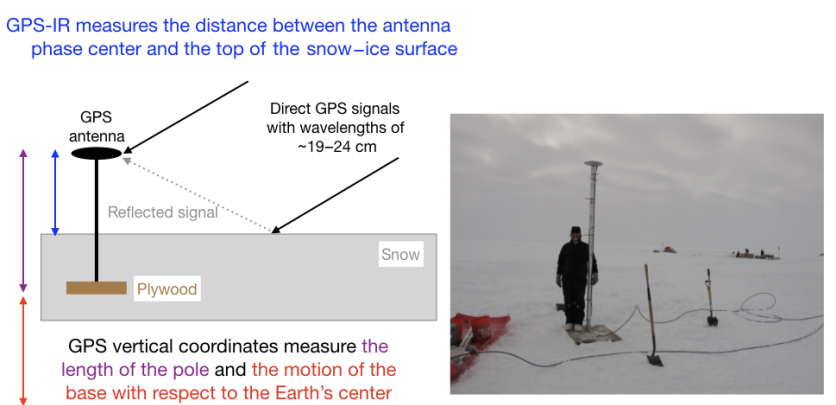

Figure 1. On the left GPS-IR geometry is shown along with a drawing of a typical GLISN installation. The reflected signal (in gray) interferes with the direct signal (black), which creates an interference pattern directly related to the reflector height (blue). The latter is defined as the distance between the GPS antenna phase center and the top of the ice-snow surface. The GPS vertical coordinates are defined relative to the center of the Earth. On the right is a photograph of GPS station GLS1 in 2011. The GPS antenna is attached to a monument made of plywood, buried $1.5 \mathrm{~m}$ below the surface at installation. Photo courtesy of IRIS.

\section{GPS data}

The original GLISN sites in Greenland are located at the DYE-2, Ice South Station, and NEEM field camps (GLS1, GLS2, GLS3). GLS3 was moved to a new monument in 2012. A fourth GPS reflection site was installed at Summit Camp in summer of 2017 (SMM3). Each GPS receiver is a dual-frequency carrier phase geodetic-quality unit. At the GLISN sites, the antenna is mounted to a pole which is attached to a plywood base and then buried $0.5-1.5 \mathrm{~m}$ below the surface. At installation the pole was $\sim 3 \mathrm{~m}$ above the ice surface. At SMM3, the antenna is attached at the top of a $16.5 \mathrm{~m}$ Rohn tower, which when installed had approximately $0.5 \mathrm{~m}$ of the tower below the surface. The GPS data for the GLISN sites are telemetered on an hourly or daily basis via Iridium modems to the UNAVCO archiving facility. Raw GPS data from all four sites are archived at UNAVCO and freely available to the public. For this study, $15 \mathrm{~s}$ GPS sampling rates and the L1 SNR GPS data were used.

\section{Summary of archived results}

Here we have archived the RH measurements with daily position results computed by the Nevada Geodetic Laboratory (2019). Figure 1 describes the similarities and differences between the two kinds of GPS measurements. RH measures the distance between the GPS antenna phase center and the top of the ice-snow surface. The geocentric vertical coordinates measure how the pole moves with respect to the center of the Earth. Both measurements are sensitive to the length of the pole that connects the antenna to the base. When the pole is extended, those pole extensions (which are identi-

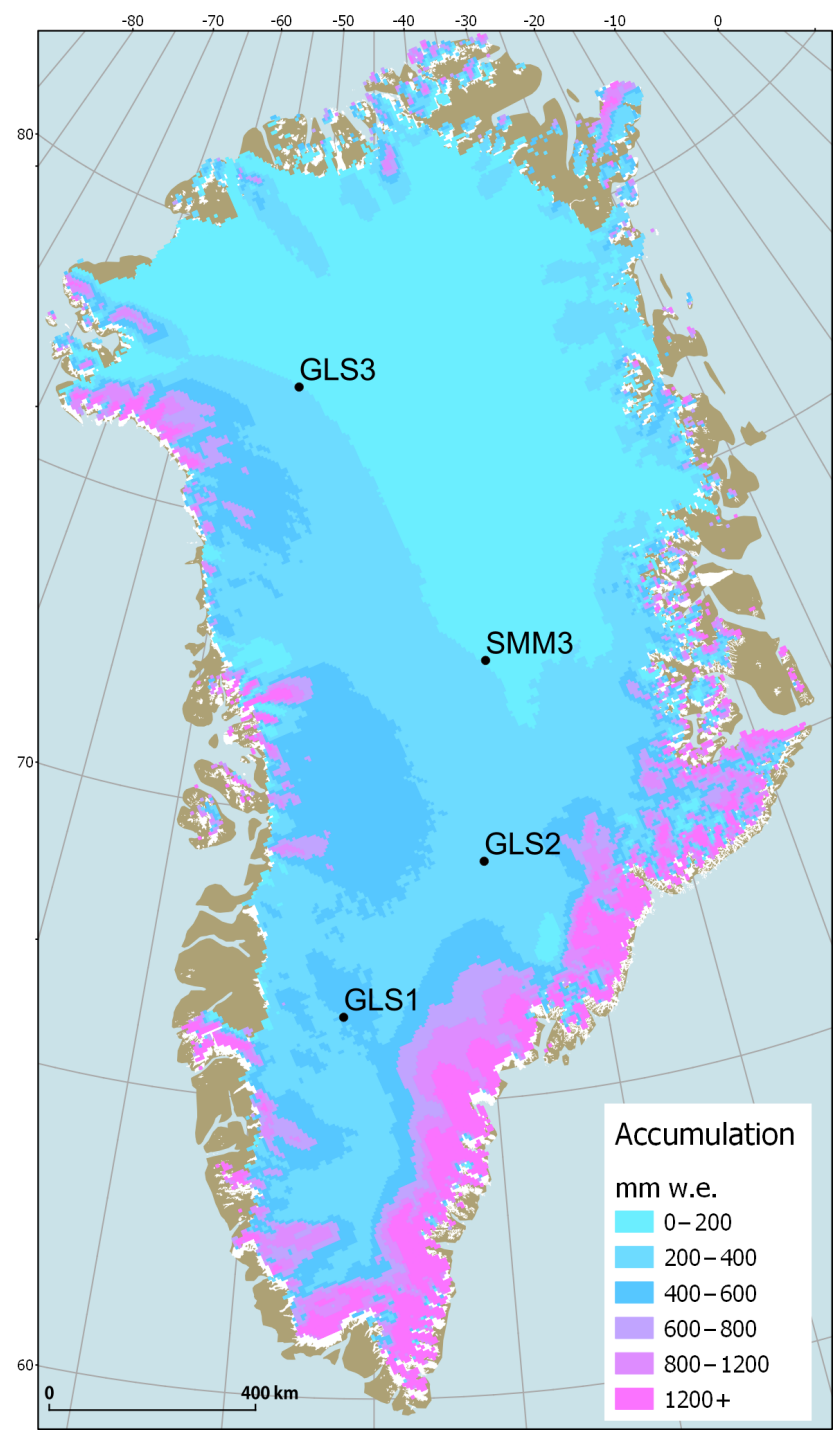

Figure 2. Map locations of the GLISN GPS sites and SMM3 (Summit Camp). Mean annual snow accumulation rates (water equivalent) are also shown (Mottram et al., 2017).

cal for the two kinds of measurements) must be corrected in both data sets.

At GLS1 only the RHs are shown (Fig. 3a). The RH measurements clearly show when the pole was lengthened, in 2016 and 2017. Elevation of the snow surface (Fig. 3b) is the mirror of the RH after the pole offsets are removed. At this site the geocentric vertical coordinates are not used except to calculate the pole extensions. At GLS2 and GLS3 both RH and geocentric vertical coordinates are shown (Fig. 3c-f). Both RH and geocentric verticals are sensitive to the length of the pole, so when the poles are extended there is an immediate and equal response in both measurements. Additionally, L2015 explained that the geocentric vertical changes reflect a combination of two effects: firn compaction between the surface and the antenna anchor point and vertical movement 

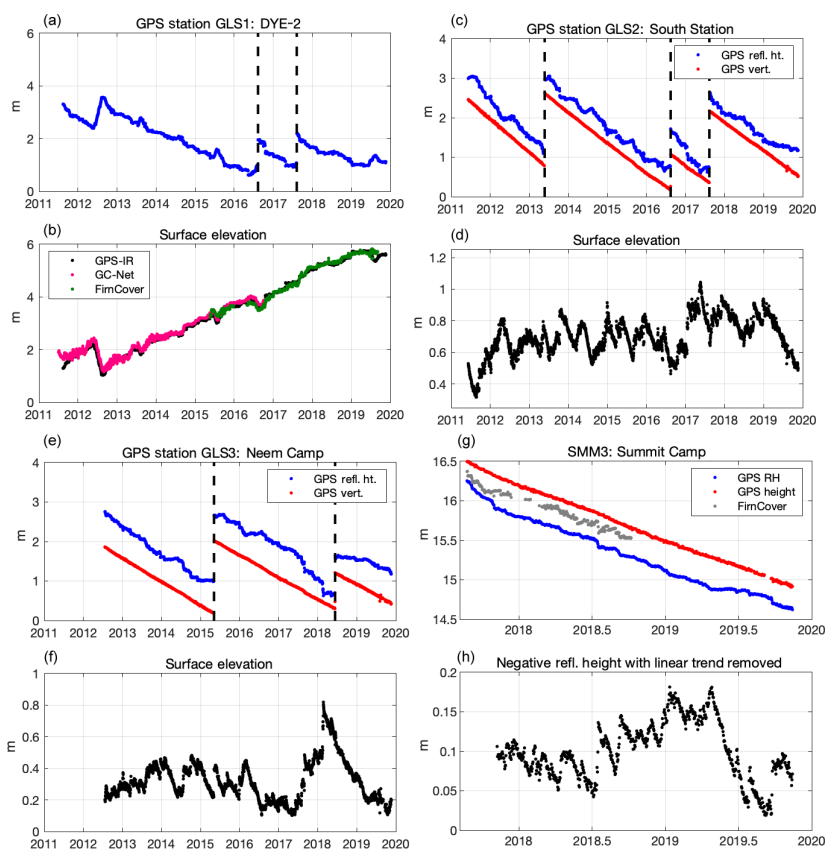

Figure 3. (a) GLS1 reflector heights; (b) surface elevation for GLS1 compared to in situ measurements from GC-Net and FirnCover; (c) GLS2 reflector heights (blue) and geocentric verticals (red); (d) surface elevation for GLS2; (e) GLS3 reflector heights (blue) and geocentric verticals (red); (f) surface elevation for GLS3; (g) SMM3 reflector heights (blue) and geocentric verticals (red), and in situ measurements from FirnCover; (h) SMM3 reflector heights with linear trend removed and sign change. All GPS verticals are defined with respect to the center of the Earth, and thus a constant has been removed before plotting them.

due to the local ice slope (derived from the GIMP elevation dataset, Howat et al., 2014). The second of these two effects is found to be small but non-negligible, 1.9 and $1.1 \mathrm{~cm} \mathrm{yr}^{-1}$ downwards for GLS2 and GLS3, respectively. The RH are affected by both new snowfall-surface melt and firn compaction. At sites with significant snow compaction effects, L2015 suggested that the effects could be removed by subtracting the geocentric vertical positions from the RH. The latter would need to be adjusted by the local slope vertical velocity, which does not affect RH. Figure $3 \mathrm{~d}$ and f show this combination, RH - (geocentric verticals + local slope velocity), with a sign change so as to indicate surface elevation changes.

Figure 3g summarizes the results for Summit Camp. Unlike the GLISN sites, which are between 1 and $3 \mathrm{~m}$ above the snow-ice surface, this GPS antenna was mounted on a $16.5 \mathrm{~m}$ tall tower. The first several months of the data records show nonlinear motion for both vertical positions and $\mathrm{RH}$, which you would expect for a taller tower with a shallow installation and relatively dry firn. We used the data from November 2017 to November 2019 to detrend the RH in order to emphasize the accumulation and melt events. The archived result file for SMM3 includes both the raw RH and the geocentric vertical coordinates. Here we have chosen not to remove effects of snow compaction.

\section{Comparison with in situ sensors}

We compare the GPS-IR snow accumulation records at DYE2 with two independent in situ snow accumulation sensors (Fig. 3a). The first is a 6-year record provided by the Greenland Climate Network, GC-Net (Steffen and Box, 2001). The GC-Net instrument is an ultrasonic snow depth sensor that has operated since 1995 . It is $\sim 2 \mathrm{~km}$ from the GPS site. It is estimated to be anchored at a depth of $15 \mathrm{~m}$ in 2011 (Koni Steffen, personal communication, 2014). The correlation between the two records is 0.993 , and the standard deviation of the difference is $9.4 \mathrm{~cm}$. The GPS-IR records between May 2015 and May 2019 are compared with another ultrasonic snow depth sensor $\sim 500 \mathrm{~m}$ from the GC-Net unit. It was installed as part of the NASA-funded Firn Compaction Verification and Reconnaissance (FirnCover) project. Similar to the GC-Net sensor, the correlation between the GPSIR records and FirnCover is very strong (0.992) and the standard deviation of the difference is $9.9 \mathrm{~cm}$. These comparisons demonstrate the fidelity of the GPS-IR records for long-term snow accumulation studies compared with established field measurements of snow depth. The 9.4 and $9.9 \mathrm{~cm}$ standard deviations of anomalies are less than or equal to the magnitude of windblown features such as sastrugi that can migrate underneath the relatively small footprints of the sonicranging sensors during their measurement periods.

\section{GPS-IR software}

GPS-IR is based on extracting characteristic frequencies found in GPS SNR data. The general principles of GPSIR and some sample datasets are provided by Roesler and Larson (2018). The code needed to apply these principles to new GPS datasets is now available at GitHub (Larson, 2019). These codes assume that the GPS data are available in the standard format known as RINEX (Gurtner, 1994). Fortran code is available to read RINEX files and compute the needed GPS-IR parameters (i.e., satellite elevation and azimuth angles). GPS-IR analysis software to routinely compute reflector heights from these files is available on GitHub in both MATLAB and Python, along with a user manual.

For cryosphere scientists who might have an interest in GPS-IR but do not have a routine need for it, a web app has been developed that automatically computes reflector heights (https://gnss-reflections.org, last access: 1 May 2020). The beta version of the app supports both data that have been archived at major GPS data centers and userprovided RINEX files (Larson, 2020). The GitHub site discussed in the previous paragraph provides a bash script that can be used to call the web app along with some examples. 


\section{Conclusions}

GPS-IR is an accurate and precise method to measure snow accumulation on ice sheets. No modifications are needed to the GPS equipment more typically used to measure accurate three-dimensional positions. Compared to ultrasonic snow depth sensors, GPS-IR has a significantly larger footprint ( $\sim 1000 \mathrm{~m}^{2}$ for an antenna that is $2 \mathrm{~m}$ above the snow-ice) and thus is more representative of a given region. GPS (and now GNSS) receivers are routinely operated in Greenland and Antarctica with excellent data retrieval records. We hope that the results shown here and the software described in this short note will lead to GPS-IR being more easily used by the cryosphere community.

Code and data availability. The code used in this study is freely available from GitHub, https://github.com/kristinemlarson (last access: 20 May 2020; Larson, 2020).

Supplement. The supplement related to this article is available online at: https://doi.org/10.5194/tc-14-1985-2020-supplement.

Author contributions. KL analyzed the data, prepared the datafiles in the Supplement, and made Figs. 1 and 3. MM made Fig. 2 and provided in situ datasets for comparisons. All authors contributed to the text of the paper.

Competing interests. The authors declare that they have no conflict of interest.

Acknowledgements. We thank Konrad Steffen for providing the GC-Net in situ snow accumulation data for DYE-2. Additional acknowledgements are found in the Supplement provided with the archived reflector height data. We thank Dean Childs and Kevin Nikolaus at IRIS PASSCAL for answering questions and providing photographs. We thank the late John Wahr for inspiring this work. The editor and two reviewers provided helpful feedback on the manuscript. Radon Rosborough and Evan Crouch helped improve the GNSS reflectometry web app.

Financial support. The FirnCover data are provided by awards NASA (grant nos. NNX10AR76G and NNX15AC62G), which also funded Michael MacFerrin's work. Kristine M. Larson's work was supported by GeoForschungsZentrum Potsdam and a research fellowship from the Alexander von Humboldt Foundation. National Science Foundation (grant no. OPP 1304011) supported the GLISN GPS sites.

Review statement. This paper was edited by Ludovic Brucker and reviewed by two anonymous referees.

\section{References}

Clinton, J. F., Nettles, M., Walter, F., Anderson, K., Dahl-Jensen, T., Giardini, D., Govoni, A., Hanka, W., Lasocki, S., Lee, W. S., McCormack, D., Mykkeltveit, S., Stutzmann, E., and Tsuboi, S.: Seismic network in Greenland monitors Earth and ice system, Eos, 95, 13-14, https://doi.org/10.1002/2014EO020001, 2014.

Greenland Climate Network: Greenland Climate Network (GCNet), available at: http://cires1.colorado.edu/steffen/gcnet/, last access: 8 October 2019.

Gurtner, W.: RINEX, The Receiver-Independent Exchange Format, GPS World, 5, 1994.

Howat, I. M., Negrete, A., and Smith, B. E.: The Greenland Ice Mapping Project (GIMP) land classification and surface elevation data sets, The Cryosphere, 8, 1509-1518, https://doi.org/10.5194/tc-8-1509-2014, 2014.

Larson, K. M.: kristinemlarson GitHub account, available at: https: //github.com/kristinemlarson, last access: 20 May 2020.

Larson, K. M.: Kristine's GNSS-IR WebApp, available at: https: //gnss-reflections.org, last access: 1 May 2020.

Larson, K. M., Gutmann, E. D., Zavorotny, V. U., Braun, J. J., Williams, M. W., and Nievinski, F. G.: Can We Measure Snow Depth with GPS Receivers?, Geophys. Res. Lett., 36, L17502, https://doi.org/10.1029/2009GL039430, 2009.

Larson, K. M., Wahr, J., and Kuipers Munneke, P.: Constraints on Snow Accumulation and Firn Density in Greenland Using GPS Receivers, J. Glaciol., 61, 101-115, https://doi.org/10.3189/2015JoG14J130, 2015.

McCreight, J. L., Small, E. E., and Larson, K. M.: Snow Depth, Density, and SWE estimates derived from GPS reflection data: validation in the western U.S., Water Resour. Res., 50, 68926909, https://doi.org/10.1002/2014WR015561, 2014.

Mottram, R., Boberg, F., Langen, P. L., Yang, S., Rodehacke, C., Christensen, J. H., and Madsen,, M. S.: Surface mass balance of the Greenland ice sheet in the regional climate model HIRHAM5: Present state and future prospects, Low Temp. Sci., 75, 105-115, https://doi.org/10.14943/lowtemsci.75.105, 2017.

Nevada Geodetic Laboratory: University of Nevada Reno Geodesy Laboratory, available at: http://geodesy.unr.edu/ PlugNPlayPortal.php, last access: 7 October 2019.

Roesler, C. J. and Larson, K. M.: Software Tools for GNSS Interferometric Reflectometry, GPS Solutions, 22, 80, https://doi.org/10.1007/s10291-018-0744-8, 2018.

Shean, D. E., Christianson, K., Larson, K. M., Ligtenberg, S. R. M., Joughin, I. R., Smith, B. E., Stevens, C. M., Bushuk, M., and Holland, D. M.: GPS-derived estimates of surface mass balance and ocean-induced basal melt for Pine Island Glacier ice shelf, Antarctica, The Cryosphere, 11, 2655-2674, https://doi.org/10.5194/tc-11-2655-2017, 2017.

Siegfried, M. R., Medley, B., Larson, K. M., Fricker, H. A., and Tulaczyk, S.: Snow accumulation variability on a west Antarctic ice sheet observed with GPS reflectometry, 2007-2017, Geophys. Res. Lett., 44, 7808-7816, https://doi.org/10.1002/2017GL074039, 2017.

Steffen, K. and Box, J.: Surface climatology of the Greenland ice sheet: Greenland Climate Network 1995-1999, J. Geophys. Res., 106, 33951-33964, 2001. 